\title{
MOBILIZAÇÃO ÉTNICA NA CIDADE DE SÃO PAULO: O CASO DOS ÍNDIÓS PANKARARU
}

\author{
MARCOS ALEXANDRE DOS SANTOS ALBUQUERQUE ${ }^{1}$
}

UFSC

\begin{abstract}
RESUMO: Este artigo analisa o papel das máscaras (praiás) dos índios Pankararu (PE) na mobilização política que ocorre na cidade de São Paulo, Brasil. Neste espaço, a tradição funciona como categoria que aproxima a oferta e a demanda de tais bens e direitos entre indios e a cidade de São Paulo. Os praiás se destacam neste mercado na medida em que estas máscaras são os elementos que mais visibilidade vêm ganhando nas apresentações destes indios. Tais apresentações se dão no contexto de inserção destes indios em dois tipos de mercado: o das artes étnicas e o dos direitos das populações indígenas.
\end{abstract}

PALAVRAS-CHAVE: direitos indígenas; pankararu; invenção de tradições; artes étnicas.

ABSTRACT: This article aims to analyze the role of the masks (praiás) of the Pankararu Indians (PE) in the political mobilization in São Paulo city, Brazil. At this place, the category of tradition works to close the demands and offer of goods and rights between Indians and the city of São Paulo. The praiás have detached in this market because they are the elements which have most visibility in the public performances of these Indians. These performances took place in the context of the insertion of these Indians into two kinds of market: the ethnical arts and Indians rights.

KEYWORDS: Indians rights; Pankararu; invented traditions; ethnic arts.

\section{Introdução}

... a gênese é independente de uma regra de
semelhança (DELEUZE, 2006, p. 262).

No relatório da Comissão Pró-Índio de São Paulo (2005, p. 05), segundo dados do IBGE, o número de indígenas que vivem na região metropolitana de São Paulo é de 59.989 indivíduos, o que dá ao estado paulista em números a terceira maior população indígena do país (atrás

\footnotetext{
${ }^{1}$ Doutorando no Programa de Pós-Graduação em Antropologia Social (PPGAS/UFSC). Membro do LEME (Laboratório de Estudos em Movimentos Étnicos/UFCG); AVAL (Antropologia Visual em Alagoas/UFAL); NAVI (Núcleo de Antropologia Visual e Estudos da Imagem/UFSC); GESTO (Grupo de Estudos sobre Rito e Performance/UFSC) e, NEIP (Núcleo de Estudos Interdisciplinares sobre Psicoativos/SP).e-mail: marcosdada@yahoo.com.br .
}

Espaço Ameríndio, Porto Alegre, v. 1, n. 1, p. 73-101, jul./dez. 2007. 
somente dos estados da Amazônia e Bahia). As principais etnias que constituem a população indígena da cidade de São Paulo são Pankararu, Pankararé, Fulni-ô, Terena, Kaingang, Kariri-Xocó, Atikum e Potiguara. No Estado de São Paulo são cerca de doze associações indígenas de diversas etnias, sendo a metade na capital. A maior parte das associações foi fundada com o intuito de fortalecer politicamente a demanda destas pessoas pela assistência diferenciada garantida pelo Estado aos povos indígenas (saúde, educação, preservação de patrimônio, território, moradia e outros).

A retórica destas associações enfatiza duas questões contemporâneas e aproxima as demandas dos índios e do Estado: a) soma-se ao discurso da ecologia (como apresentou Albert (2002) e Conklin (2002) para o contexto amazônico). Apelando em nome de uma historicidade oficial, - que congelou no passado a presença indígena e naturalizou sua invisibilidade no quadro econômico brasileiro e global o índio aparece como detentor/protetor natural de determinados recursos sociais; e b) soma-se ao discurso da proteção/preservação das tradições indígenas - pelos órgãos públicos (FUNAI, IPHAN, e outros) e ONG's - como ampliação da democracia (fortalecimento do Estado de Direito).

Na cidade de São Paulo, contemporaneamente, há uma evidente mobilização social/étnica em torno de políticas para a proteção/preservação das tradições indígenas. As associações indígenas de São Paulo apelam a este tipo de tradição principalmente em duas circunstâncias: a) como espaço de receita econômica na apresentação de tradições indígenas em arenas específicas (museus, igrejas, universidades e outros) e b) na conquista e geração de direitos indígenas junto aos órgãos públicos.

Além de aumentar a possibilidade de uma renda eventual, as apresentações indígenas e de sua cultura (material e imaterial) em arenas específicas, acabou se tornando também um novo, rico, prestigiado e por isso, restrito espaço de mobilização coletiva e de visibilidade de um componente social historicamente marginalizado. Assim, a visibilidade de uma tradição indígena em arenas específicas se tornou um grande instrumento de visibilidade de demandas políticas de parte desta população indígena urbana. Como espaço de receita 
MARCOS ALEXANDRE DOS SANTOS ALBUQUERQUE - Mobilização étnica na...

econômica, estas arenas acabam se constituindo num espaço de mobilização dos grupos indígenas e de suas associações que procuram, cada uma a sua maneira, apresentar uma forma de organização de sua tradição indígena (COMISSÃO DE DIREITOS HUMANOS DA ASSEMBLÉIA LEGISLATIVA DE SÃO PAULO, 2002; COMISSÃO PRÓ-ÍNDIO DE SÃO PAULO, 2005; MATTA, 2007).

O modelo tomado para tais apresentações de tradições nestas arenas é a representação oficial das tradições indígenas. A construção arbitrária deste modelo, e de sua homogeneidade, pode ser paradigmaticamente observada numa arena/espaço institucional privilegiado, os museus. Penso tais instituições como zonas de contato (CLIFFORD, 1999), como um espaço institucional privilegiado de organização da representação do encontro colonial,

the space in which peoples geographically and historically separated come into contact with each other and establish ongoing relations, usually involving conditions of coercion, radical inequality, and intractable conflict (CLIFFORD, 1999, p.192).

Organizando um passado imaginário e monopolizando o espaço social de representação do índio, o museu impõe à representação das tradições indígenas o duplo papel de: a) anonimato; e b) de neutralidade histórica e espacial (CLIFFORD, 1999; 1998b; PRICE, 2000). Os museus são paradigmáticos porque dão visibilidade à historicidade oficial ao invisibilizar a violência da ocupação colonial pela preservação de uma história assimiliacionista, compensatória e democrática. Se nos museus "national sensibilities are respected, the exploits and connoisseurship of dominant groups are respected" (CLIFFORD, 1999, p. 209), tais espaços negam, portanto, dar visibilidade ao caráter contemporâneo, plural e contra-hegemônico destas tradições indígenas.

Em termos de análise penso estas arenas como o "lugar" da representação, isso é, como uma categoria social não essencialista, uma "política de localização" (WOODWARD, 2003, p. 54). Este “lugar" é ambíguo, pois é um espaço onde o poder (enquanto estratégia e método $^{2}$ ) tende a monopolizar a representação (WOODWARD, 2003, p. 52-53). Como a força que pretende produzir a homogeneidade da

${ }^{2}$ Cf. Foucault (1977).

Espaço Ameríndio, Porto Alegre, v. 1, n. 1, p. 73-101, jul./dez. 2007. 
representação "é diretamente proporcional à sua invisibilidade" (SILVA, 2003, p. 83), há sempre o perigo de naturalizar uma normatização, porque ela "é um dos processos mais sutis pelos quais o poder se manifesta no campo da identidade e da diferença" (SILVA, 2003, p. 83). Estas arenas são, portanto, ao mesmo tempo: a) o espaço da visibilidade da atuação do Estado (ampliação do Estado de Direito); b) o espaço da luta pela institucionalização de um modelo de representação; e, c) o espaço do jogo da sincronicidade das representações nativas com a oficial.

O termo normatização se refere à política de "eleger arbitrariamente - uma identidade específica como o parâmetro em relação ao qual as outras identidades são avaliadas e hierarquizadas" (SILVA, 2003, p. 83) ${ }^{3}$. Na representação oficial do jogo político há a construção da homogeneização e invisibilidade das lutas sociais operadas nele (reivindicações econômicas, educacionais, judiciais, e outras), como mostraram Abélès (1997), Abélès e Jeudy (1997), e Geertz (1991) no plano do simbólico, e L'Estoile (2002) e Kuper (2002) no da gênese das categorias sociais e científicas. Assim, a condição intrínseca destas arenas é a da heterogeneidade social e da diversidade das demandas.

Este texto é um exercício de análise do papel destas arenas específicas (museus, igrejas, universidades e outros) da cidade de São Paulo na mobilização étnica dos índios Pankararu (PE) em torno da construção de uma tradição indígena, a máscara ritual praiá. Em textos anteriores (Albuquerque 2005a; 2005b) ao discutir a política de reconhecimento dos Kapinawá (PE) como índios pelo Estado brasileiro, apresentei o repertório musical do ritual do toré entre estes índios como uma tradição inventada (HOBSBAWN, 1984; LINNEKIN, 1983; HANDLER, 1984; HANDLER \& LINNEKIN, 1984) no sentido de que "o fenômeno da geração de tradições se refere à criação de uma substância histórica ou cultural que será operada pelo grupo criador em sua etnicidade" (GRÜNEWALD, 2001 b, p. 10) ${ }^{4}$.

\footnotetext{
${ }^{3}$ Para o arbitrário da representação oficial do componente "indígena" na constituição do quadro social brasileiro ver, por exemplo, Tacca (2001) e Lima (1995).

${ }^{4}$ Nestes textos, eu estava identificado com uma série de trabalhos sobre a temática indígena no nordeste brasileiro (BARBOSA, 2003 e 2005; GRÜNEWALD, 2001a e 2002; MENDONÇA, 2003; NASCIMENTO, 1994; PALITOT, 2005; SAMPAIO, 1993 e 1994; SILVA, 2004; VALLE, 1993), principalmente orientado por uma antropologia histórica (OLIVEIRA, 1988, 1993, 1999a e 1999b).
} 


\section{O caso dos Pankararu do Real Parque}

Os índios Pankararu formam uma população de cerca de 4.000 pessoas que habitam uma área demarcada de 8.100 ha (sendo mais 6.194 ha reivindicados) (MORGADO \& SENA, 2007; MATTA, 2005 e 2007; SANDRONI et. al., 2005; ARRUTI, 1996 e 1999; CARNEIRO DA CUNHA, 1999; PETI, 1993) entre as cidades de Tacaratu, Petrolândia e Itaparica no sertão de Pernambuco, Brasil. Como grande parte da população migrante que fugiu das dificuldades econômicas do sertão nordestino em busca de melhores oportunidades de renda na cidade de São Paulo, os Pankararu começaram a migrar para São Paulo nos anos de 1940, e mais intensamente nas décadas de 1950-60 (MATTA, 2005 e 2007, ARRUTI, 1996 e 1999), desde então essa migração se tornou constante ${ }^{5}$.

Hoje essa população de migrantes, já na quarta geração, se concentra no Real Parque, em uma "favela" no bairro do Morumbi, à beira do rio Pinheiros na capital paulista. O cálculo dessa população na cidade de São Paulo não é preciso: 1.500 índios em Arruti (1999) e Matta (2007); 1.200 no relatório da Comissão de Direitos Humanos da Assembléia Legislativa de São Paulo (2002); 1.000 em Carneiro da Cunha (1999); 1.000 em Medeiros (2004); e 950 em Cosso (2002). No Real Parque essa população é de 116 famílias e 513 pessoas (MATTA, 2007). Essa comunidade vem, aproximadamente há treze anos, construindo uma organização política e tentando assim ampliar seus direitos junto aos órgãos públicos. Os Pankararu do Real Parque foram assim o primeiro grupo indígena urbano a ser reconhecido pela FUNAI em São Paulo (SAMPAIO, 2005).

No Real Parque existem duas associações indígenas Pankararu: a) Associação S.O.S. Comunidade Indígena Pankararu, fundada em 1994 e presidida por Manuel Alexandre Sobrinho, o Sr. Bino; b) ONG Ação Cultural Indígena Pankararu, fundada em 2003 e presidida por Dimas

\footnotetext{
${ }^{5}$ Para uma visão de um período histórico mais antigo conferir Hohenthal Jr. (1960a e 1960b) e Pinto (1938 e 1991).
} 
MARCOS ALEXANDRE DOS SANTOS ALBUQUERQUE - Mobilização étnica na...

Joaquim do Nascimento Pankararu ${ }^{6}$. Como resultado de sua mobilização política os Pankararu do Real Parque contam com: um ambulatório indígena (no hospital do Morumbi); assistência da FUNAl, através da Administração Executiva Regional (AER) de Bauru; projeto de programa de coleta seletiva para reciclagem; Projeto Pindorama que desde 2001 dá bolsas de estudos para alunos indígenas, mantido pela PUC de São Paulo, Pastoral Indigenista da Arquidiocese de São Paulo e FUNAI (MORI, 2003; NICOLETTI, 2002); O Senac-SP (e Faculdades Radial) através do programa Formatos 500 (desde março de 2003) assessora e dá apoio técnico ao projeto Protagonismo Juvenil com a Arte Pankararu (PANKARARU, 2005).

Como espaço privilegiado de tais mobilizações políticas, o apelo e a visibilidade de uma tradição indígena funciona como categoria que aproxima, neste mercado específico, a oferta e a demanda de tais bens e direitos entre índios e a cidade de São Paulo. Os praiás se destacam neste mercado na medida em que esta máscara é o elemento que mais destaque vem ganhando nas apresentações públicas destes índios na cidade de São Paulo. Tais apresentações se dão no contexto de inserção destes índios em dois tipos de mercado: o das artes étnicas e o dos direitos das populações indígenas. Ao darem visibilidade à sua condição de índios e reivindicarem sua legitimidade pela apresentação pública dos praiás, há uma organização social na comunidade que dialoga com a categoria tradição como antigo e novo, ortodoxia e heterodoxia, em dois grandes planos: a) como bem simbólico no mercado das artes étnicas da cidade de São Paulo, entre lutas pelo poder de monopólio deste campo, no sentido de Bourdieu (1989 e 2004); e, b) na visibilidade da ação estatal, de órgãos públicos, Igreja (CIMI) e de ONG's pela concretização dos direitos indígenas e ampliação da democracia brasileira.

É o campo (BOURDIEU, 1989 e 2004) destas artes étnicas que está se apresentando como um novo componente da mobilização indígena na capital paulista. Este campo de disputa (em torno da legitimidade de seu conteúdo e regras) parece se apresentar como uma nova agência

\footnotetext{
${ }^{6}$ Esta ONG produziu junto com o LISA (Laboratório de Imagem e Som em Antropologia) da USP (Universidade de São Paulo) o belo documentário sobre a migração pankararu Do São Francisco ao Pinheiros (70') (2007) dirigido por Paula Morgado e João Claudio de Sena (MORGADO \& SENA, 2007).
} 
MARCOS ALEXANDRE DOS SANTOS ALBUQUERQUE - Mobilização étnica na...

política na mobilização étnica, com uma atuação diferente ao da Igreja (CIMI) e do Estado (FUNAI). A existência deste mercado permite que as artes étnicas sejam acessíveis a um grande público em centros de apresentações como museus, galerias, feiras, escolas, faculdades, instituições de pesquisa, e órgão públicos. Este mercado se constitui num espaço distinto, aparentemente autônomo, que possibilitou uma visibilidade original para as demandas políticas e econômicas desta população indígena urbana. É a cidade de São Paulo que permite através de um mercado original e singular a emergência do praiá como uma tradição indígena, como uma nova modalidade de renda, de visibilidade social e por isso de mobilização política.

\section{Da perda à invenção de tradições nos índios do Nordeste do Brasil.}

Uma importante questão da bibliografia sobre as comunidades indígenas do nordeste do Brasil é a aculturação, entendida como a perda irreparável da tradição (da cultura), na medida em que esta é pensada como uma essência ordenadora da vida social. Mas contemporaneamente esta categoria passou da analítica da aculturação para a da invenção (OLIVEIRA, 1999a).

Assim, esta noção de perda (aculturação), antes de dar conta de um fenômeno real, é uma categoria discursiva que nos informa melhor sobre as representações daqueles que a cunharam do que sobre $o$ fenômeno em $\mathrm{si}^{7}$. Do mesmo modo que na análise de Durval $M$. Albuquerque (1999) - no contexto da construção da identidade da região Nordeste do Brasil -, lançar mão de um modelo estereotipado de um componente social marginalizado (o índio) virou consenso entre as ideologias de esquerda e de direita que reivindicam, cada uma a seu modo, o monopólio da representação da assimilação dos diferentes componentes sociais na formação do Estado-nação Brasil.

Assim, nas ideologias da identidade nacional (de direita e de esquerda) a imagem do índio se dá ou pela aproximação do indígena com a natureza (como quase sinônimos), ambos representados pelas imagens da autenticidade, da preservação e do distanciamento da

\footnotetext{
${ }^{7}$ Cf. Tacca (2001) e Lima (1995).
} 
MARCOS ALEXANDRE DOS SANTOS ALBUQUERQUE - Mobilização étnica na...

contemporaneidade ("civilização") como condição para sobreviver ou, por outro lado, inversamente, cooptado pelas imagens da nação brasileira moderna, que busca então sua identidade num eufemismo, a assimilação da diferença.

Carneiro da Cunha (1992) interroga sobre a legitimidade das representações sobre o contato entre os povos nativos do Brasil e o europeu colonizador. Para esta autora, um mecanismo sociológico quase sempre ausente das pesquisas sobre o contato foi a questão da agência. Através da introdução da questão da agência um alerta é lançado contra as naturalizações de que são vítimas estas regiões de discurso (a ciência). Contra uma representação do contato - e de um estereótipo do índio (o natural, ancestral, tradicional e redundante) Carneiro da Cunha chama os índios para a arena da história e da etnologia ao se referir a uma possível história indígena, onde "a gênese do homem branco e a iniciativa do contato - sejam freqüentemente apreendidos nas sociedades indígenas como o produto de sua própria ação ou vontade" (CARNEIRO DA CUNHA, 1992, p. 8).

A herança da categoria aculturação na antropologia moderna vem com o culturalismo norte-americano que pensou a questão do contato intersocietário pautado num paradigma antropológico que focava apenas a "cultura" como objeto, conseqüentemente também sua "perda" em termos de aculturação (REDFIELD et. al., 1936) -, no Brasil a escola foi seguida por Galvão (1979) e Ribeiro (1982). Na antropologia inglesa o termo mais usado foi neste campo foi o de mudança cultural (MALINOWSKI, 1938), onde a análise das mudanças culturais segue três ordens: o impacto da cultura mais forte, a substância da cultura nativa e o fenômeno de trocas autônomas resultantes da relação entre as duas culturas (ibid.).

Roberto Cardoso de Oliveira (1963 e 1964) elabora a categoria de fricção interétnica a partir de uma leitura rigorosa de K. Marx, especialmente $O 18$ de Brumário de Luís Bonaparte (1974). A teoria da fricção interétnica é uma teoria sobre a etnicidade, e não sobre a cultura como no culturalismo e na escola de Malinowski. A teoria da fricção interétnica aponta neste sentido marxista para um "equivalente lógico, mas não ontológico da luta de classes" (MENEZES BASTOS, 1996, p. 178), onde "a existência de uma das sociedades dialeticamente nega a 
MARCOS ALEXANDRE DOS SANTOS ALBUQUERQUE - Mobilização étnica na...

da outra, assim se configurando a contradição que descreve sua modalidade de relação" (ibid.) ${ }^{8}$.

Esta caracterização opta, teórica e metodologicamente, pela visualização da ação e do dado. Para Gluckman (1963), a política deve ser analisada como um processo e não um tema inclusivo da cultura (sociedade), aqui ele se opõe a Evans-Pritchard e M. Fortes e suas tipologias de sistemas políticos elaboradas no livro African Political Systems de 1940. Ao analisar o que denominou de rituais de rebelião, Gluckman (1963) trabalhou com a idéia de community e não sociedade, pois a idéia de comunidade

não supõem limites espaciais bem delimitados, nem unidades em termos de código de orientação cultural, mas somente que sejam partilhados determinados padrões de interação no comportamento cotidiano dos indivíduos uns para os outros (OLIVEIRA, 1988, p. 39).

Para Gluckman "community não [é] um grupo harmonioso e bem integrado, e sim um conjunto de pessoas cooperando e disputando dentro dos limites de um sistema estabelecido de relações e culturas" (GLUCKMAN, 1987, p. 303). Por isso não é possível postular um ponto zero da mudança cultural, ou seja, não é possível postular um momento histórico exato da mudança cultural, pois tal ponto zero da mudança cultural não existe.

Acredito como L' Estoile (2002) e Kuper (2002), que uma genealogia dos conceitos de sociedade e cultura esclarece a retórica do Estado-nação e de seus intelectuais (filósofos, juristas, sociólogos, antropólogos, artistas e folcloristas) no sentido da construção arbitrária das divisões e normatização das hierarquias do espaço social. Para Oliveira (1999b, p. 55), devemos fazer no plano analítico uma divisão entre a narrativa histórica convencional e uma "possível história indígena, que corresponde à atualização, dentro de determinada conjuntura, de uma forma narrativa da tradição". A ausência deste ponto de vista na etnologia brasileira colocou as populações indígenas do

\footnotetext{
${ }^{8}$ Por isso é interessante fazer uma crítica à idéia de sociedade como "interioridade" (RAPPORT \& OVERING, 2000a e 2000b), já que as sociedades são sistemas abertos, a idéia de "perda da cultura" deve ser explorada a partir da crítica a equivalência entre sociedade e sistema de significação limitado a si mesmo.
} 
nordeste do Brasil num espaço marginal dentro da academia, com poucos estudos etnográficos até a década de 1980.

Foi nos fins da década de 1980 que grande parte da população cabocla e indígena da região nordeste começou a procurar os órgãos públicos para reivindicarem o seu reconhecimento como comunidade indígena. Tais demandas tiveram peso suficiente para iniciar um novo diálogo na Antropologia brasileira. Assim, por exemplo, no Museu Nacional (UFRJ) é desenvolvido o projeto Fronteiras Étnicas, Território e Tradição Culturaß ${ }^{\beta}$, orientado teoricamente por uma Antropologia histórica (OLIVEIRA, 1988, 1993, 1999a e 1999b) que passou a entender e definir as populações indígenas não pelo critério da permanência de elementos culturais contrastivos (diacríticos), mas sim observando que

a descontinuidade que instaura os povos indígenas no nordeste não é, portanto, conseqüência de uma diferença cultural, mas sim uma produção da instância política, calcada em fatores históricos (OLIVEIRA, 1993, p. vii $)^{10}$.

A contrapelo da narrativa histórica oficial devemos estar atentos para demarcar as categorias e as experiências que constituem uma historicidade nativa própria, Bhabha lembra que:

A representação da diferença não deve ser lida apressadamente como o reflexo de traços culturais ou étnicos preestabelecidos, inscritos na lápide fixa da tradição. A articulação social da diferença, da perspectiva da minoria, é uma negociação complexa, em andamento, que procura conferir autoridade aos hibridismos culturais que emergem em momentos de transformação histórica (BHABHA, 1998, p. 20-21).

$\mathrm{Na}$ representação da cultura que reencena o passado, se "introduz outras temporalidades culturais incomensuráveis na invenção da tradição" (BHABHA, 1998, p. 21). Bhabha identifica no discurso das minorias a imposição de uma temporalidade própria, uma leitura contra hegemônica,

\footnotetext{
${ }^{9}$ E também o "Projeto Levantamento de Terras Indígenas no Estado da Bahia (PINEB)" coordenado por Pedro Agostinho da Silva e Maria Rosário G. de Carvalho na UFBA.

${ }^{10}$ Ver coletânea organizada por Oliveira (1999a).
} 
uma idéia do novo como ato insurgente de tradução cultural. Essa arte não apenas retoma o passado como causa social ou precedente estético; ela renova o passado, reconfigurando-o como um 'entre-lugar' contingente, que inova e irrompe a atuação do presente (BHABHA, 1998, p. 27).

Para entender as demandas políticas dos povos indígenas e a legitimidade de suas tradições contemporâneas, passa-se necessariamente pela crítica da imagem do índio construída pela imagética do Estado-nação. Ao se fazer tal crítica o argumento é construído a partir dos mecanismos de reconhecimento e legitimidade elaborados por tais povos. Para tanto é a etnografia a grande ferramenta, pois, ela

acentua a importância dos modos pelos quais os atores sociais definem por si mesmos, as condições em que vivem. Com a extensão do significado de cultura - de textos e representações para práticas vividas -, considera-se em foco toda produção de sentido (GRÜNEWALD, 2002).

\section{A mobilização étnica Pankararu em São Paulo: o praiá e a "segunda roupa"}

$\mathrm{Na}$ área Pankararu em Pernambuco o toré é o nome tanto de um ritual quanto de um tipo de dança e música. Os torés (músicas) são entoados na parte final de um ritual, ocasião que também é chamada de toré ou "brincadeira", espaço lúdico de participação coletiva. Já os praiás são as máscaras corporais que "vestem" os Encantados" (entidades sobrenaturais) durante um ritual, para eles são dirigidos toantes (cânticos) próprios. Simplificando sobremaneira se pode dizer que o toré, no seu conjunto, apesar de sagrado é público e tem características profanas. O praiá (máscara corporal, Encantado, toante) é restrito a rituais religiosos. O toré é então realizado fora da área Pankararu, como exibição de identidade e força política, os praiás pelo seu caráter mais

\footnotetext{
11 “Os Encantados são 'índios que se encantaram', voluntária ou involuntariamente, e por isso o culto a eles, como insistem os Pankararu, não pode ser confundido com o culto aos mortos, identificado como a 'religião de negros"” (ARRUTI, 1999, p. 269).
} 
sagrado ficam restritos às aldeias (MATTA, 2005 e 2007; SANDRONI et. al., 2005; ARRUTI, 1996 e 1999; CARNEIRO DA CUNHA, 1999).

Manuel Alexandre Sobrinho, o Sr. Bino, líder da Associação S.O.S. Comunidade Indígena Pankararu em São Paulo, mantém um grupo de exibição do toré e dos praiás que se apresenta em diversos locais, como escolas públicas, igrejas e faculdades particulares. Fizeram apresentações na Assembléia Legislativa (SP) e no Centro Cultural Banco do Brasil (CCBB-SP), tiveram uma participação no programa Planeta Som da Rádio USP, duas músicas gravadas com a cantora Simone Soul, e um CD, produzido por Alfredo Bello para o selo Mundo Melhor, com toantes e torés intitulado Índios Pankararu da comunidade Real Parque de São Paulo-SP, lançado em 2007.

Como aponta Price (2000, p. 101), nas chamadas artes étnicas há uma evidente estratégia de seleção dos seus conteúdos e significados culturais, e isso porque a apresentação de tais conteúdos implica um projeto político. No caso da mobilização étnica no Real Parque estas considerações dizem algo sobre a exibição pública dos praiás. Segundo um informante (o paulista Alexandre Pankararu) a idéia de ter as vestimentas dos praiás para apresentações na capital paulista surgiu há três ou quatro anos, contudo, segundo ele, as máscaras "não contêm a semente".

Para entender o que essa frase significa é necessária uma pequena síntese de como se dá o "levantamento" de um praiá (MATTA, 2005 e 2007; ARRUTI, 1996 e 1999; CARNEIRO DA CUNHA, 1999). Tudo começa com o aparecimento da "semente" que "é a forma material por que os Encantados se manifestam pela primeira vez aos Pankararu" (ARRUTI, 1999, p. 269). Os Encantados escolhem uma pessoa para zelar por eles, aparecem em sonho, as informam de suas intenções e lhe entregam a "semente". Ela é então guardada em um pote e enterrada no solo embaixo da casa do "zelador" (a pessoa que fica então responsável pela guarda e preservação das máscaras corporais dos praiás). Deste modo os Encantados passam a se manifestar no "particular" (culto doméstico), neste espaço eles revelam seu nome e seu toante (cântico) próprio. Depois disso o Encantado pede para ser "levantado", ou seja, cultuado no toré (espaço público). Neste momento então é que o "zelador" constrói (tece) a indumentária característica dos praiás. Este 
"zelador" convoca então, em sigilo, um homem jovem da comunidade para "vestir" o praiá. Para esta função o jovem deve ser alguém de reconhecida boa conduta, pois assumir esta função é um privilégio e um destaque social (ARRUTI, 1999, p. 271).

Arruti (ibid.) informa que também "não é qualquer pessoa que é reconhecida como apta a receber uma 'semente', estando esse lugar marcado por certa avaliação coletiva acerca de sua reputação". O "zelador" passa a concentrar em torno de si a realização de "particulares" e deve manter um "terreiro" para as cerimônias públicas (torés, por exemplo). Segundo Carneiro da Cunha (1999), é possível classificar o número de praiás em três gerações: a) treze praiás iniciais; b) mesmo com a presença de faccionalismos o número de praiás cresceu em apenas algumas unidades; c) hoje o número de praiás ultrapassa os cinqüenta ${ }^{12}$. O autor informa que "esses novos praiás não são levados em consideração pelos mais velhos do grupo" (CARNEIRO DA CUNHA, 1999, p. 56-57), pois eles não os vêem como parte da tradição.

A posse de um praiá (...) determina, até certo ponto, poder político dentro do grupo. Ou seja, para os mais velhos a proliferação de praiás significa a fragmentação de poder, o que leva o grupo a grandes cisões (CARNEIRO DA CUNHA, 1999, p. 56-57).

Assim, a construção de uma tradição indígena (praiás) como instrumento de visibilidade política e econômica na comunidade do Real Parque coloca o problema da legitimidade desta tradição e dos praiás. No encarte do $\mathrm{Cd}$ para o selo Mundo Melhor, citado acima, a antropóloga e pesquisadora dos Pankararu, Priscilla Matta (2007, p. 14), escreve:

Em São Paulo, em 1994, havia somente um praiá. (...) No entanto, os pankararu compraram e levaram da aldeia de Pernambuco as fibras de caroá para a confecção das vestimentas de outros praiás no Real Parque. (...) dez praiás, sendo dois para crianças, foram 'levantados' em São Paulo, no ano de 2000.

\footnotetext{
${ }^{12}$ Para dados antigos ver Pinto (1938 e 1991).
} 
O "levantamento" desses praiás em São Paulo só foi possível com o consentimento dos responsáveis no Brejo dos Padres, pois estes praiás têm os mesmos nomes de praiás da aldeia em Pernambuco. Matta (ibid. p. 14-15) continua,

Os pankararu consideram essa a 'segunda roupa', pois o 'tronco velho' está no Brejo dos Padres. (...) Em São Paulo, como não dispõem de terreiro, espaço sagrado, dançam o toré com os praiás em festas e comemorações que denominam 'apresentações'.

A autora ainda informa que eles dançam o Toré nestas "apresentações" porque este tem um caráter mais lúdico e político, e porque serve de referência para as crianças do que é a tradição Pankararu (ibid., p. 15).

\section{O social como espaço de análise processual}

Como a mobilização política dos Pankararu em São Paulo, através de suas associações, organizou uma pauta de reivindicações junto ao Estado e a construção de uma tradição indígena? Acredito que as arenas específicas para a visibilidade dessas tradições indígenas é a especificidade da cidade de São Paulo. Tais arenas são também o espaço de intersecção da heterogeneidade de demandas dos nativos, da luta pelo monopólio da representação da imagem do índio e de visibilidade das ações governamentais. Tais arenas formam o que estou chamando aqui de campo (BOURDIEU, 1989 e 2004) das artes étnicas da cidade de São Paulo, espaço que permite que tradições indígenas possam ser exibidas e "consumidas", implicando assim numa nova agência para a mobilização política indígena na capital paulista.

O modelo tomado para as apresentações de tradições indígenas nestas arenas é a representação oficial da imagem do índio. Tal modelo é, paradigmaticamente, o do museu, o museu como zona de contato (CLIFFORD, 1999). Como dito anteriormente, monopolizando o espaço social de representação do índio, o museu impõe à representação das tradições indígenas o duplo papel de anonimato e de neutralidade histórica e espacial (CLIFFORD, 1999 e 1998b; PRICE, 2000). Na 
MARCOS ALEXANDRE DOS SANTOS ALBUQUERQUE - Mobilização étnica na...

representação do encontro colonial que o museu veicula, o índio está fora da história da natureza (ele é ecologia) e da sociedade (ele precisa ser preservado, conservado para sobreviver), sua agência e contemporaneidade são minimizadas, quando não invisibilizadas.

O museu ao mesmo tempo invizibiliza a heterogeneidade do espaço social nativo pois "such institution tend to reflect unifield community visions rather than overlapping, discrepant histories" (CLIFFORD, 1999, p. 208), ele impõe um modelo homogêneo, normatizando e organizando arbitrariamente a historicidade e dinâmica da representação da tradição (ou "cultura") do outro. O encontro colonial é eufeminizado e naturalizado nos museus através da organização de discursos comuns que se legitimam ao se auto referenciarem. O melhor exemplo está nos discursos e representações que a arte, a ciência e os textos jurídicos constroem sobre o índio, a partir da idéia de preservação da tradição destes pela assimilação democrática de sua "cultura" (CLIFFORD, 1998b). Tais discursos portanto invisibilizam a contemporâneidade, a heterogeneidade e o caráter contra-hegemônico destas tradições indígenas.

Walter Benjamin, em A Obra de Arte no Tempo de suas Técnicas de Reprodução diz que "no tempo das técnicas de reprodução, o que é atingido na obra de arte é a sua aura" (BENJAMIN, 1969, p. 19) e isso porque a sua reprodução depreende "o objeto reproduzido do domínio da tradição" (ibid., p. 20). Benjamin anuncia algo muito significativo, na medida em que "a tradição é uma realidade bastante viva, extremamente mutável" (ibid., p. 22), "o critério de autenticidade não é mais aplicável" (ibid., p. 24), pois saímos do campo do assim chamado ritual para o campo da "práxis política" (ibid.). H. Bhabha lembra que Benjamin, em $A$ tarefa do tradutor, colocou esta questão do seguinte modo, "a tradução [...] deve [...] passar para a sua própria língua o modo de significar do original. [...] o original e a tradução devem ser identificados como fragmentos de uma linguagem maior" (BHABHA, 1998, p. 238). Penso que o processo de tradução no social é esta linguagem maior. Assim, este texto entende a etnicidade como processo social (BARTH, 1998) e justaposição de tradições (FISCHER, 2000), numa determinada situação histórica (OLIVEIRA, 1988) onde a representação do índio é vista como uma política da recipro-identidade. 


\section{Política da recipro-identidade}

Acredito que é interessante ter como condição de análise a ocorrência de lógicas intermediárias (ou lógicas da tradução) que estão localizadas no espaço social, no "local" da representação. É na etnografia que se deve demonstrar tal lógica da tradução. E tal etnografia, acredito, deve ser feita nos moldes propostos por G. Marcus de etnografia modernista (1991) e multi-situada (1998), e na dialógica de Clifford (1998a), tal modelo de etnografia preza por descrever os vários pontos de vista que estão em jogo, que não se cancelam, nem se somam, mas revelam suas divisões e alianças.

Este tipo de etnografia deve problematizar a dominação e a legitimação de representações e revelar, tal como fez Menezes Bastos (1996) -, ao analisar a relação/encontro do cantor de rock Sting com o ativista indígena Raoni -, que "abordar o encontro em consideração como um sistema de representações simbólico-culturais encaixadas não parece ter maior rendimento explanatório, pois sua dualidade essencial (...) sempre resultará irredutível" (ibid., p. 167-8). Para Menezes Bastos (ibid.) não há "soma possível" no encontro colonial, "e, então, não se trata, para buscar entendê-lo, de saber se uma das lógicas em contato dominantemente se sobrepõe ou não à outra ou se tais lógicas somadas fazem nascer uma terceira (...): o encontro colonial constitui uma 'relação de contradição'".

O campo (BOURDIEU, 1989 e 2004) das artes étnicas provoca uma nova situação histórica (OLIVEIRA, 1988) para a etnicidade Pankararu, que é atualizada então na sua "práxis política". Acredito aqui que é rentável assumir para a análise deste quadro social a existência de alguns níveis de intercomunicação que podem ser analisados como processos, no sentido explorado por Taussig (1993). A partir de uma leitura livre da obra de W. Benjamin, Taussig recupera o argumento de Benjamin sobre a relação de irredutibilidade das categorias gêmeas "autêntico" e "cópia". Para Taussig as identidades étnicas (sociais) podem ser entendidas como contrapostas a outras identidades numa 
MARCOS ALEXANDRE DOS SANTOS ALBUQUERQUE - Mobilização étnica na...

espécie de efeito óptico, vê-las a contrapelo, no espelho. A cópia é o "híbrido" real, mais real que o original.

A partir de Mimesis and Alterity de M. Taussig (1993) formulei a questão daquilo que estou denominando de política da reciproidentidade. Neste texto, Taussig analisa o modo como as populações autóctones da Colômbia e América Central absorveram o contato violento com o colonizador. O autor aponta que o instrumento de resistência destas populações foi recorrentemente "copiar" o colonizador em uma forma que pudesse ter certo poder sobre ele, estas formas geralmente eram objetos de culto religioso (ícones), o que implica numa hibridização de elementos culturais e mudanças semânticas profundas nas relações destas populações com seus objetos rituais (ícones). Este é o pano de fundo para Taussig teorizar sobre a construção das identidades sociais, afirmando que a construção destas identidades está na dinâmica da organização social da alteridade no contato colonial.

Assim, no encontro colonial, a alteridade é também um outro lado da mimese e seu inverso, pois a diferença é "capturada", reproduzida num modelo, que é ao mesmo tempo o outro, mas sob a forma (modelo novamente) do mesmo, mimese. Deste modo, toda a discursividade (e administração) deste encontro passou pela estratégia de "recortar" o outro, de "modelá-lo" a fim de torná-lo semelhante, e com isso criar poder sobre este outro, poder criado no momento em que o outro é "capturado", administrado. As ênfases dessa discursividade revelam os modelos em disputa pela hegemonia sobre a representação do encontro colonial, e é aí que os discursos sobre a diferença e a mimese se interpenetram e criam estratégias de inclusão uns nos outros (TAUSSIG, 1993, p. 236).

A mimese surge para Taussig a partir de uma leitura de Walter Benjamin. Em Benjamin a faculdade mimética é um recurso para se torna (become) e se comportar (behave) "like something else" (TAUSSIG, 1993, p. 19). A habilidade da mimese é a habilidade de uma pessoa se tornar o outro (pessoa). A mimese é tanto a semelhança quanto a diferença, "being like, and of being Other" (ibid., p. 129) porque na mimese não se procura continuar o mesmo (cópia literalmente), mas "maintaining sameness through alterity" (ibid.). Taussig mostra como os índios Cuna 
MARCOS ALEXANDRE DOS SANTOS ALBUQUERQUE - Mobilização étnica na...

(norte da Colômbia e Panamá) construíram uma identidade de indígenas a partir do encontro com o colonizador europeu e depois norteamericano.

Foi somente a partir de um determinado período histórico dos Cuna que a representação de uma indianidade Cuna foi necessária. Ela foi construída como uma estratégia política ao mesmo tempo contrahegemônica e de reivindicação de direitos junto ao Estado-Nação. $O$ pitoresco da história Cuna, o que é muito esclarecedor, foi o fato de que parte desta população era formada por pessoas de "cor" branca. Através da imagem da mulher e da "brancura" Cuna foi possível instituir uma diferença (indianidade) ao mesmo tempo em que se constituiu um espaço de valorização da igualdade (pela referência às representações românticas da mulher e da "brancura" no ocidente) (TAUSSIG, 1993, p. 176).

O caso dos índios Cuna estudados por Taussig é expressivo, como enfatiza o autor, "by remaining resolutely 'themselves', resolutely alter vis à vis old Europe as well as - not clearly -its black slaves, the Cuna have been able to 'stay the same' in a world of forceful change" (TAUSSIG, 1993, p. 129). Assim, é no espaço social de relação entre colonizador e povo Cuna que uma tradição indígena (a "brancura" da mulher) se apresenta no primeiro plano da política de uma identidade indígena. A estratégia Cuna para sobreviver ao colonialismo europeu e depois norte-americano foi "a política da mimese e da alteridade" (ibid., p. 137), e isso ocorreu no "mosaico hierárquico das alteridades" construído pelo colonizador, no plano de suas preferências (alteridades ora como positivas e ora como negativas) (ibid., p. 144). Mimese e alteridade "energizing each other, so that the more you see the phenomenon as mimetic, as 'like us', the greater you make the alterity, and vice versa" (ibid., p. 174).

\section{Portanto, o simulacro...}

As identidades são construídas frente aos Estados-Nação (e também à Mass Média como mostrou Ginsburg (2002)), isso significa que entre o "original" e a "cópia" há todo um processo social de tradução, há em 
particular dois: a) o da religião Pankararu de Pernambuco (privado) para a autoria (laico) do praiá na cidade de São Paulo (exibição pública); e b) há a mobilização em torno da máscara praiá devido ao monopólio pelos órgãos oficiais e pelas mass média (GINSBURG, 2002) das representações que organizam a doxa da imagem do índio. A tradução se dá dentro de um campo monopolizado por uma representação oficial e midiática, que formula um modelo homogêneo do componente social indígena, o índio genérico na sua ancestralidade, distância, anonimato e homogeneidade social.

A tradução é uma "traição" (como no italiano), pois a cópia simula os dois (há por isso um sentido de autoria da cópia). Assim, os praiás do Real Parque, como "a segunda roupa", são o simulacro, pois, "o simulacro apreendeu uma disparidade constituinte na coisa que ele destitui do lugar de modelo" (DELEUZE, 2006, p. 106). Por simulacro não devemos entender uma simples imitação, mas, sobretudo,

o ato pelo qual a própria idéia de um modelo ou de uma posição privilegiada é contestada, subvertida. [...] toda semelhança tendo sido abolida, sem que se possa, por conseguinte, indicar a existência de um original e uma cópia. É nessa direção que é preciso procurar as condições não mais da experiência possível, mas da experiência real (seleção, repetição, etc.) (DELEUZE, 2006, p. 109).

A identidade de um objeto (a máscara praiá) pode assim ser apresentada num quadro onde dois antagonismos se compõe: a) o utilitarismo (dia-bólico na expressão de Menezes Bastos (1996) ${ }^{13}$ contra cópia infinita (inautenticidade); e, b) a tradição indígena (sim-bólico) (autenticidade).

A tradução que se faz no social é sempre uma certa forma de autoria. Price (2000, p. 87) insiste na dimensão histórica da arte, e critica o chamado "presente etnográfico" porque este "isola a expressão cultural do fluxo do tempo histórico" (PRICE, 2000, p. 88). Do mesmo modo critica a idéia de que a "Arte Primitiva" é ditada e mantida pelo costume (tradição) (PRICE, 2000, p. 90-1), pois a natureza do símbolo cultural é

13 "O simulacro é precisamente uma imagem demoníaca, destituída de semelhança, ou, antes, contrariamente ao ícone, ele colocou a semelhança no exterior e vive de diferença" (DELEUZE, 2006, p. 186.). 
histórica, e acompanha a dinâmica das mudanças sociais. Grünewald (2001b) utiliza o conceito de "etnicidades reconstruídas" para se referir ao incremento étnico como resultado das relações de transações comerciais globais, que permitem aos grupos a "restauração, preservação e recriação de atributos étnicos" (GRÜNEWALD, $2001 \mathrm{~b}, \mathrm{p}$. 4-5).

Não seria então o espaço urbano da capital paulista um lugar que promoveria a "restauração, preservação e recriação de atributos étnicos" (ibid.) pela existência de arenas específicas? Penso que devemos superar a dicotomia autêntico versus simulacro para perceber a renovação da cultura, e perceber que "o simulacro (feira, museu, etc.) pode ser arena para exibição de autênticas renovações culturais e de novas reflexividades sobre a identidade étnica" (GRÜNEWALD, 2001b, p. 1112). A criação de um mercado afeta o modus de produção, papel e significado de objetos de Arte (ou ritual) (PRICE, 2000, p. 114-115), mas não os destituem da qualidade de autênticos (SAPIR, 1970) ${ }^{14}$ e nem da de tradicionais (HOBSBAWN, 1984; LINNEKIN, 1983; HANDLER, 1984; HANDLER \& LINNEKIN, 1984; GRÜNEWALD, 2001 a).

A produção deste elemento de cultura implica uma profunda reorganização do espaço político, religioso e cultural. As formas como estas produções são negociadas por diferentes atores sociais permitem reconhecer representações diversas sobre a tradição indígena na capital paulista. Barth (2000, p. 117) ao procurar "ver a cultura como conhecimento, pensá-la como conhecimento, em vez de, mais genericamente, como cultura", entender que a circulação e reconhecimento de valores culturais deve levar em conta que

para descobrir significados no mundo dos outros precisamos ligar um fragmento de cultura e um determinado ator(a) à constelação particular de experiências, conhecimentos e orientações desse/dessa ator(a) (BARTH, 2000, p. 128).

\footnotetext{
14 "Sapir's notion of genuineness refers to the possibility of creativity. Genuine cultures provide individuals both with a rich corpus of pre-established (traditional) forms and with the opportunity to 'swing free' (1949, p. 322) in creative endeavors that inevitably transform those forms. For Sapir, genuine culture has a dialectical quality, for it embodies the seeds of its own transformation" (HANDLER e LINNEKIN, 1984, p. 287).
} 
A cultura é distributiva, os fenômenos sociais que a envolvem são diferentemente vividos pelos atores, por isso "precisamos incorporar ao nosso modelo de produção da cultura uma visão dinâmica da experiência como resultado da interpretação de eventos por indivíduos" (BARTH, 2000, p. 129). Aliado a isso, não se deve menosprezar o problema do poder de definição das estruturas simbólicas que pretendem monopolizar a representação de determinado aspecto social (BOURDIEU, 1989 e 2004; MARCUS, 1991; WOLF, 2003). E ainda, como diz Woodward (2003, p. 59), precisamos apontar para as "posições-desujeito" que os atores tomam como não sendo de puro livre arbítrio, mas como o lugar da "interpolação" (ibid.). Toda representação é um traço visível (seja ela arte, categorias sociais, linguagem e mesmo o poder) (ibid., p. 89), uma política da identidade. A identidade social é uma recipro-identidade porque toda categoria social é um agenciamento, é uma multiplicidade. O praiá, como simulacro (DELEUZE, 2006), esconde e revela a autoria/tradução (cultural e política) como condição da heterogeneidade do espaço social.

Os praiás do Real Parque revelam duas grandes questões da política da identidade: a luta por direitos e, conseqüentemente, a ampliação do poder do estado ao monopolizar tanto os modelos de valorização da diferença (assimilação democrática e homogeneidade dos componentes sociais marginalizados) quanto o acesso a estes direitos (e bens/goods). Este texto apresentou uma análise do papel de determinadas arenas (museus, igrejas, universidades, e outros) da cidade de São Paulo na mobilização étnica dos índios Pankararu e em torno da constituição de uma tradição indígena (a máscara praiá). Estas arenas foram descritas como formando simultaneamente: a) o espaço da visibilidade da atuação do estado (ampliação do Estado de Direito); b) o espaço da luta pela institucionalização de um modelo de representação; e, c) o espaço do jogo da sincronicidade da(s) representação(ões) nativa(s) com a oficial.

Nietzsche (1980) argumentava que todo conceito, ou palavra, é um recorte do mundo dos sentidos, e sendo da ordem humana é arbitrária. Toda palavra, na famosa expressão de E. Cioran (1989), nasce neutra, por isso, elas (como a linguagem do social, suas traduções) carregam em si a história da política de sua identidade, cabe ao 
pesquisador, para não naturalizá-la ou reificá-la, fazer-lhe a genealogia (FOUCAULT, 2000) ${ }^{15}$.

\section{Referências bibliográficas}

ABÉLÈS, Marc. La Mise en Représentation du Politique. In: ABÉLES, Marc; JEUDY, Henri-Pierre (Orgs.). Anthropologie du Politique. Paris: Armand Colin, 1997. p. 247271.

ABÉLÈS, Marc e JEUDY, Henri-Pierre. Introduction. In: ABÉLES, Marc; JEUDY, Henri-Pierre (Orgs.). Anthropologie du Politique. Paris: Armand Colin, 1997. p. 5-24.

ALBERT, Bruce. O Ouro Canibal e a Queda do Céu. Uma Crítica Xamânica da Economia Política da Natureza (Yanomami). In: ALBERT, Bruce; RAMOS, Alcida R. (Orgs.). Pacificando o Branco: Cosmologias do Contato no Norte Amazônico. São Paulo: Editora da UNESP, 2002. p. 240-274.

ALBUQUERQUE, Durval M. A Invenção do Nordeste e outras Artes. Recife: FJN, Ed. Massangana; São Paulo: Cortez, 1999.

ALBUQUERQUE, Marcos A. S. O ToréCoco (o forgar lúdico dos índios Kapinawá da Mina Grande- PE). In: GRÜNEWALD, Rodrigo de Azeredo. Toré: Regime Encantado dos Índios do Nordeste. Recife: Ed. Massangana (FUNDAJ), 2005a. p. 257-82.

O ToréCoco (a construção do repertório musical tradicional dos índios Kapinawá da Mina Grande - PE). Dissertação (Mestrado em Sociologia), Campina Grande: PPGS/UFCG, 2005b.

APPADURAI, Arjun. Disjunção e Diferença na Economia Cultural Global. In: FEATHERSTONE, Michel (Org.). Cultura Global: Nacionalismo, Globalização e Modernidadde. Petrópoles: Vozes, 1994. p. 311-327.

ARRUTI, José Maurício P.A. O Reencantamento do Mundo: trama histórica e arranjos territoriais Pankararu. Dissertação (Mestrado em Antropologia Social), Rio de Janeiro: PPGAS/MN/UFRJ, 1996.

A árvore Pankararu: fluxos e metáforas da emergência étnica no sertão do São Francisco. In: OLIVEIRA, João Pacheco de (Org.). A Viagem de Volta: Etnicidade, Política e Reelaboração Cultural no Nordeste Indígena. Rio de Janeiro: Contra Capa, 1999.

15 "Delineou-se assim o que se poderia chamar uma genealogia, ou melhor, pesquisas genealógicas múltiplas, ao mesmo tempo redescoberta exata das lutas e memória bruta dos combates. E esta genealogia, como aclopamento do saber erudito e do saber das pessoas, só foi possível e só se pode tentar realizá-la à condição de que fosse eliminada a tirania dos discursos englobantes com suas hierarquias" (FOUCAULT, 2000, p. 170). 
MARCOS ALEXANDRE DOS SANTOS ALBUQUERQUE - Mobilização étnica na...

BARBOSA, Wallace de Deus. Pedra do Encanto: dilemas culturais e disputas políticas entre os Kambiwá e os Pipipã. Rio de Janeiro: Contra Capa Livraria / LACED, 2003.

. O Toré (e o praiá) entre os Kambiwá e os Pipipã: performances, improvisações e disputas culturais. In: GRÜNEWALD, Rodrigo de Azeredo. Toré: Regime Encantado dos Índios do Nordeste. Recife: Ed. Massangana (FUNDAJ), 2005. p. 155-171.

BARTH, Frederik. Grupos Étnicos e suas Fronteiras. In: POUTIGRAT, Philippe; STREIFF-JENART. Teorias da Etnicidade. São Paulo: Editora da UNESP, 1998. p. $185-250$.

O Guru, o Iniciador e Outras Variações Antropológicas. In. LASK, Tomke (Org.). Rio de Janeiro: Contra Capa, 2000.

BENJAMIN, Walter. A Obra de Arte no Tempo de suas Técnicas de Reprodução. In: VELHO, G. (Org.). Sociologia da Arte IV. Rio de Janeiro: Zahar, 1969. p. 15-47.

BHABHA, Homi K. O Local da cultura. Belo Horizonte: Ed. UFMG, 1998.

BOURDIEU, Pierre. O Poder Simbólico. Lisboa: Difel, 1989.

Campo de poder, campo intelectual e habitus de classe. In:

economia das trocas simbólicas. São Paulo: Perspectiva, 2004. p. 183-202.

CARDOSO DE OLIVEIRA, Roberto. Aculturação e fricção interétnica. In: América Latina, Rio de Janeiro, v. 6, n. 3, p. 33-46, 1963.

O Índio e o mundo dos brancos: a situação dos Tikuna no Alto Solimões. Difel: São Paulo, 1964.

CARNEIRO DA CUNHA, Manuela. Introdução. In: História dos índios no Brasil. São Paulo: FAPESP/Companhia das Letras/SEC. Municipal de Cultura, 1992. p. 9-24.

CARNEIRO DA CUNHA, Maximiliano. A Música Encantada Pankararu (toantes, toré, ritos e festas na cultura dos índios Pankararu). Dissertação (Mestrado em Antropologia Cultural), Recife: UFPE, 1999.

CASTRO, Celso. Apresentação. In: (Org.). Franz Boas: Antropologia Cultural. Rio de Janeiro: Jorge Zahar Ed., 2004. p. 07-23.

CIORAN, Emili M. Breviário de Decomposição. Tradução de José Thomaz Brum. Rio de Janeiro: Rocco, 1989.

CLIFFORD, James. Sobre a Autoridade Etnográfica. In: GONÇALVES, José Reginaldo Santos. A experiência etnográfica: Antropologia e Literatura no séc. XX. Rio de Janeiro: Ed. UFRJ, 1998a. p. 17-62. 
Sobre o Surrealismo Etnográfico Sobre. In: GONÇALVES, José Reginaldo Santos. A experiência etnográfica: Antropologia e Literatura no séc. XX. Rio de Janeiro: Ed. UFRJ, 1998b. p. 132-178.

. Museums as Contact Zones. IN: Routes: Travel and Translation in the Late Twentieth Century. Cambridge: Harvard University Press, 1999. p. 188-219.

COMISSÃO DE DIREITOS HUMANOS DA ASSEMBLÉIA LEGISLATIVA DO ESTADO DE SÃO PAULO. Vamos Ouvir a Voz dos que Não tem Vez: Relatório das Audiências Públicas sobre a Situação dos Povos Indígenas no Estado de São Paulo. São Paulo: Publicação do mandato do Deputado Estadual Renato Simões (PT/SP), 2002.

COMISSÃO PRÓ-ÍNDIO DE SÃO PAULO. Índios na Cidade de São Paulo. Organização de Selma Gomes. Relatório da Comissão Pró-Índio de São Paulo. São Paulo, 2005.

CONKLIN, Beth A. Shamans Versus Pirates in the Amazonian Treasure Chest. In: American Anthropologist, Menasha, Wisconsin, 104 (4), p. 1050-1061, 2002.

COSSO, Roberto. Alckmin faz ocas em reservas indígenas. Folha de São Paulo, São Paulo, 23 jun. 2002.

DELEUZE, Gilles. Diferença e Repetição. Tradução de Luiz Orlandi e Roberto Machado. Rio de Janeiro: Graal, 2006.

FISCHER, Michael. La etnicidad como texto y modelo. In: MARCUS, George; FISCHER, Michael. La antropologia como crítica cultural. Buenos Aires: Amorrortu editors, 2000. p. 250-55.

FORTES, Maier; EVANS-PRITCHARD, Eduard E. African Political Systems. London: Oxford University Press, 1970.

FOUCAULT, Michel. Microfísica do poder. Rio de Janeiro: Edições Graal, 2000.

GALVÃO, Eduardo. Encontro de Sociedades. Rio de Janeiro: Paz \& Terra, 1979.

GEERTZ, Clifford. Negara: O Estado Teatro no Século XIX. Rio de Janeiro: Bertrand, 1991.

GINSBURG, Faye D. et al. Introduction. In: Media Worlds: Anthropology on New Terrain; Berkeley: University of California Press, 2002. p. 1-36.

GLUCKMAN, Max. Order and Rebellion in Tribal Africa. London: Cohen \& West, 1963.

Análise de uma Situação Social na Zululândia Moderna. In: FELDMANBIANCO, Bela (Org.). Antropologia das Sociedades Contemporâneas. São Paulo: Global, 1987. p. 227-344. 
MARCOS ALEXANDRE DOS SANTOS ALBUQUERQUE - Mobilização étnica na...

GRÜNEWALD, Rodrigo de A. Os índios do descobrimento: tradição e turismo. Rio de Janeiro: Contra Capa Livraria, 2001a.

- Turismo, Cultura e Identidade Étnica. In: $24^{\text {a }}$ Reunião Brasileira de Antropologia. Olinda, 2001b.

Caracterização inicial dos estudos culturais para reunião como professores do Centro de Humanidades/UFCG. Campina Grande: UFCG, no prelo, 2002.

HANDLER, Richard. On Sociocultural Discontinuity: Nationalism and Cultural Objectification in Quebec. Current Anthropology, v. 25, n. 1. p. 55-71, 1984.

HANDLER, Richard; LINNEKIN, Jocelyn S. Tradition, Genuine or Spurious. Journal of American Folklore, Illinois, v. 97, n. 385, p. 273-290, 1984.

HOBSBAWM, Eric. Introdução: A Invenção das Tradições. In: HOBSBAWN, E.; RAGER, T. (Orgs.). A Invenção das Tradições. Rio de Janeiro: Paz e Terra, 1984, p. 09-23.

HOHENTHAL JR. William D. As tribos indígenas do médio e baixo São Francisco. Revista do Museu Paulista, Nova Série, São Paulo, v. XII, p. 37-71, 1960a.

The general characteristics of Indian cultures in the Rio São Francisco valley. Revista do Museu Paulista, Nova Série, São Paulo, v. XII, p. 73-86, 1960 b.

KUPER, Adam. Nomes e Partes: as categorias antropológicas na África do Sul. In: L'ESTOILE, Benoit; NEIBURG; Federico; SIGAUD, Lygia (Orgs.). Antropologia, Impérios e Estados Nacionais. Rio de Janeiro: Relume Dumará, 2002. p. 39-60.

L'ESTOILE, Benoit de. Ciência do homem e "dominação racional”: saber etnológico e política indígena na África colonial francesa. In: L'ESTOILE, Benoit; NEIBURG; Federico; SIGAUD, Lygia (Orgs.). Antropologia, Impérios e Estados Nacionais. Rio de Janeiro: Relume Dumará, 2002. p. 61-93.

LIMA, Antonio Carlos de Souza. Um olhar sobre a presença das populações nativas na invenção do Brasil. In: SILVA, Araci Lopes da; GRUPIONI, L. D. A Temática Indígena na Escola. Brasília: MEC/MARI/UNESCO, 1995. p. 407-419.

LINNEKIN, Jocelyn. S. Defining Tradition: Variations on the Hawaiian Identity. American Ethnologist, 10 (2), p. 241-252, 1983.

MALINOWSKI, Bronislaw. Introductory Essay: the Anthropology of Changing African Cultures. In: MAIR, L. (Ed.). Methods of Study of Cultural Contact in Africa. International Institute of African Languages and Culture (Memorandum XV). London: Oxford University Press, 1938. p. vii-xxxviii. 
MARCOS ALEXANDRE DOS SANTOS ALBUQUERQUE - Mobilização étnica na...

MARCUS, George. Identidades passadas, presentes e emergentes: requisitos para etnografias sobre a modernidade no final do século XX ao nível mundial. Revista de Antropologia, São Paulo, n. 34, 1991.

- Ethnography in/of the World System: The Emergence of Multi-Sited Ethnography. In: Ethnography through Thick \& Thin. Princeton: Princeton University Press, 1998. p. 79-104.

MARCUS, George; FISCHER, Michael. La antropologia como crítica cultural. Buenos Aires: Amorrortu editors, 2000.

MARX, Karl. O 18 de Brumário de Luís Bonaparte. In: Os Pensadores. Trad. de Leandro Konder. São Paulo: Ed. Abril S. A. Cultural e Industrial, 1974. p. 329-410.

MATTA, Priscila Matta. Dois Elos da Mesma Corrente: Uma Etnografia da Corrida do Umbu e da Penitência entre os Pankararu. Dissertação (Mestrado em Antropologia Social), São Paulo: USP, 2005.

MEDEIROS, Marcelo. Mantendo as Raízes. Revista do Terceiro Setor, São Paulo, 2004.

MENDONÇA, C. F. L. Os índios da Serra do Arapuá: Identidade, território e conflito no sertão de Pernambuco. Dissertação (Mestrado em Antropologia Social), Recife: UFPE, 2003.

MENEZES BASTOS, Rafael José de. Musicalidade e Ambientalismo na Redescoberta do Eldorado e do Caraiba: Uma Antropologia do Encontro Raoni-Sting. Revista de Antropologia, São Paulo, 39(1), p. 145-189, 1996.

MORI, Kiyomori. Etnia garante bolsa. Folha de São Paulo, São Paulo, 28 jan. 2003.

NASCIMENTO, Marco Tromboni de S. A jurema: das ramas até o tronco. Ensaio sobre algumas categorias de classificação religiosa. Salvador: mimeo, 1994.

NICOLETTI, André. Projeto dá bolsa para índio fazer faculdade. Folha de São Paulo, São Paulo, 01 jan. 2002.

NIETZSCHE, Friedrich. Sobre Verdade e Mentira no Sentido Extra-Moral. In: Os Pensadores, Friedrich Nietzsche, 2 ed. São Paulo: Abril Cultural, 1980.

OLIVEIRA, João Pacheco de. O Nosso Governo: Os Ticuna e o Regime Tutelar. São Paulo: Marco Zero, 1988.

A Viajem da volta: reelaboração cultural e horizonte político dos povos indígenas do Nordeste. In: Atlas das terras indígenas do Nordeste. Rio de Janeiro: PETI/PPGAS/Museu Nacional/UFRJ, 1993. p. v-viii. 
MARCOS ALEXANDRE DOS SANTOS ALBUQUERQUE - Mobilização étnica na...

Uma Etnologia dos 'Índios Misturados'? Situação Colonial, Territorialização e Fluxos Culturais. In: (Org.). A Viagem de Volta: Etnicidade, Política e Reelaboração Cultural no Nordeste Indígena. Rio de Janeiro: Contra Capa, 1999a. p. 11-36.

Ensaios em antropologia histórica. Rio de janeiro: Editora UFRJ, 1999 b.

PALITOT, Estevão Martins. Os Potiguara da Baía da Traição e Monte-Mór: História, Etnicidade e Cultura. Dissertação (Mestrado em Sociologia), João Pessoa: UFPB, 2005.

PANKARARU, Dimas Joaquim do Nascimento Pankararu. Índios Pankararu de São Paulo (símbolos da resistência Nacional). Projeto encaminhado ao Governo Federal dentro do Programa da Carteira Indígena. São Paulo, 2005.

PETI - Projeto Estudo sobre Terras Indígenas no Brasil. In: Atlas das Terras Indígenas do Nordeste. Rio de Janeiro: PETI/PPGAS/Museu Nacional/UFRJ, 1993.

PINTO, Estevão. Alguns aspectos da cultura artística dos Pancarús de Tacaratu. Revista do Serviço do Patrimônio Histórico e Artístico Nacional, Rio de Janeiro, n. 2, 1938.

. As Máscaras-de-dança dos Pancararu de Tacaratu (Remanescentes Indígenas dos

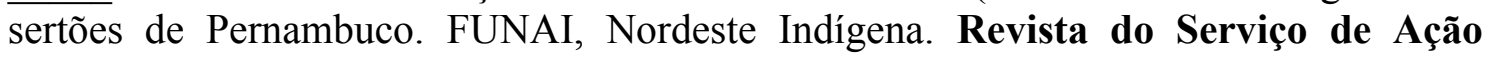
Cultural da $3^{\text {a }}$ SUER - FUNAI, Recife, p. 05-15, 1991.

PRICE, Sally. Arte Primitiva em Centros Civilizados. Tradução de Inês Alfano; revisão técnica de José Reginaldo Santos Gonçalves. Rio de Janeiro: Editora UFRJ, 2000 .

RAPPORT, Nigel; OVERING, Joanna. Culture. In: Social and Cultural Anthropology: The Key Concepts. Londres: Routledge. 2000a. p. 92-102.

. Society. In: Social and Cultural Anthropology: The Key Concepts. Londres: Routledge, 2000b. p. 333-343.

RIBEIRO, Darcy. Os Índios e a Civilização: a integração das populações indígenas no Brasil moderno. 3 ed. Petrópolis: Vozes, 1982.

REDFIELD, Robert; LINTON, Ralph; HERSOVITZ, Melville J. Memorandum on the Study of Acculturation. American Anthropologist, Menasha, Wisconsin, v. 38, p. 149$152,1936$.

SAMPAIO, José Augusto Laranjeiras. Kapinawá: O povo que venceu os grileiros. Boletim da ANAÍ-Bahia (Associação Nacional de Apoio ao Índio), n. 10-11, p. 8-9, jan.-jun. 1993. 
. Notas sobre a formação histórica, etnicidade e constituição territorial do povo Kapinawá. In: Reunião Anual da Associação Nacional de Pós-Graduação e Pesquisa em Ciências Sociais (ANPOCS), Caxambu-MG, 1994.

SAMPAIO, Rafael. Índios urbanos enfrentam desemprego na periferia de SP. Agência Carta Maior, São Paulo, 07 jun. 2005.

SANDRONI, Carlos; VILAR, Gustavo; ACSELRAD, Maria. Torés Pankararu ontem e hoje. In: GRÜNEWALD, Rodrigo de Azeredo (Org.). Toré: Regime Encantado dos Índios do Nordeste. Recife: Ed. Massangana (FUNDAJ), 2005. p. 283-97.

SAPIR, Edward. Cultura "Autêntica" e "Espúria". In: PIERSON, Donald. Estudos de Organização Social: Leituras de Sociologia e Antropologia Social; Tomo II. São Paulo: Livraria Martins Editora, 1970. p. 282-311.

SILVA, Roosevelt H. Potyguara: Turismo e Etnicidade. Monografia (Graduação em Ciências Sociais - Antropologia), Campina Grande: UFCG, 2004.

SILVA, Tomaz Tadeu da. A produção social da identidade e da diferença. In: SILVA, Tomaz Tadeu da (Org.). Identidade e Diferença: a perspectiva dos estudos culturais. 2 ed. Petrópolis: Vozes, 2003. p. 73-102.

STEIL, Carlos A. Antropologia do Turismo: Comunidade e Desterritirialização. In: 24 a Reunião Brasileira de Antropologia. Olinda - PE, 2001.

TACCA, Fernando de. A Imagética da Comissão Rondon: Etnografias Fílmicas Estratégicas. Campinas: Papirus, 2001.

TAUSSIG, Michel. Mimesis and Alterity: A Particular History of the Senses. New York: Routledge, 1993.

VALLE, Carlos Guilherme Otaviano do. Terra, Tradição, e etnicidade: um estudo dos Tremembé do Ceará. Dissertação (Mestrado em Antropologia), Rio de Janeiro: PPGAS/MN/UFRJ, 1993.

Experiência e semântica entre os Tremembé do Ceará. In: OLIVEIRA, João Pacheco de (Org.). A Viagem de Volta: Etnicidade, Política e Reelaboração Cultural no Nordeste Indígena. Rio de Janeiro: Contra Capa, 1999. p. 279-337.

WOLF, Eric R. Introduction. In: . Europe and the People without History. Los Angeles and Berkeley, University of California Press, 1982. p. 03-23. . Inventing Society. American Ethnologist, 15 (4), p. 752-761, 1988.

. Encarando o poder: velhos insights, novas questões. In: FEELDMANBIANCO, Bela; RIBEIRO, Gustavo Lins (Orgs.). Antropologia e Poder, Contribuições de Eric Wolf. Brasília: EdUnb, 2003. p. 325-343. 
WOODWARD, Hathryn. Identidade e Diferença: uma introdução teórica e conceitual. In: SILVA, Tomaz Tadeu da (Org). Identidade e Diferença: a perspectiva dos estudos culturais. 2 ed. Petrópolis: Vozes, 2003. p. 07-72.

\section{Outras referências}

\section{CD de Música}

MATTA, Priscila. Índios Pankararu da comunidade Real Parque de São Paulo-SP. CD produzido por Alfredo Bello, para a série BPF Brasil Passado e Futuro, selo Mundo Melhor. São Paulo-SP, 2007

\section{Vídeo (DVD)}

MORGADO, Paula; SENA, João Claudio de. Do São Francisco ao Pinheiros. (70'). Produzido pela ONG Ação Cultural Indígena Pankararu e LISA (Laboratório de Imagem e Som em Antropologia) / USP (Universidade de São Paulo), dirigido por Paula Morgado e João Claudio de Sena; São Paulo-SP, 2007. 